\title{
BMJ Open Caffeine consumption during pregnancy and ADHD at the age of 11 years: a birth cohort study
}

\author{
Bianca Del-Ponte, ${ }^{1}$ Iná S Santos, ${ }^{1}$ Luciana Tovo-Rodrigues, ${ }^{1}$ Luciana Anselmi, ${ }^{1}$ \\ Tiago N Munhoz, ${ }^{1}$ Alicia Matijasevich ${ }^{1,2}$
}

To cite: Del-Ponte B, Santos IS, Tovo-Rodrigues L, et al. Caffeine consumption during pregnancy and ADHD at the age of 11 years: a birth cohort study. BMJ Open 2016;6:e012749. doi:10.1136/bmjopen-2016012749

- Prepublication history for this paper is available online To view these files please visit the journal online (http://dx.doi.org/10.1136/ bmjopen-2016-012749).

Received 23 May 2016 Revised 20 October 2016 Accepted 25 October 2016

CrossMark

\begin{abstract}
${ }^{1}$ Postgraduate Program in Epidemiology, Federal University of Pelotas, Pelotas, Brazil

${ }^{2}$ Department of Preventive Medicine, School of Medicine, University of São Paulo, São Paulo, Brazil
\end{abstract}

Correspondence to Dr Bianca Del-Ponte; bianca.delponte@gmail.com

\section{ABSTRACT}

Objective: Studies evaluating caffeine intake during pregnancy and long-term outcomes, such as the child's neurobehaviour, are still scarce and their results are inconsistent. The objective of the present study was to evaluate the association between maternal consumption of caffeine during pregnancy and attention deficit hyperactivity disorder (ADHD) at the age of 11 years.

Methodology: All children born in the city of Pelotas, Brazil, during the year 2004, were selected for a cohort study. The mothers were interviewed at birth to obtain information on coffee and yerba mate consumption during pregnancy, among other matters. At the age of 11 years, presence of ADHD was evaluated using the Development and Well-Being Assessment (DAWBA) questionnaire, applied to the mothers. The prevalence of ADHD was calculated, with $95 \% \mathrm{Cls}$. The association between caffeine consumption and ADHD was tested by means of logistic regression.

Results: 3485 children were included in the analyses. The prevalence of ADHD was $4.1 \%(95 \%$ Cl $3.4 \%$ to $4.7 \%): 5.8 \%(95 \% \mathrm{Cl} 4.7 \%$ to $6.9 \%)$ among boys and $2.3 \%(95 \% \mathrm{Cl} 1.5 \%$ to $3.0 \%)$ among girls. The prevalence of caffeine consumption during the entire pregnancy and in the first, second and third trimesters was $88.7 \%(87.7 \%$ to $89.7 \%)$, $86.5 \%$ ( $85.4 \%$ to $87.5 \%), 83.0 \%$ ( $81.8 \%$ to $84.2 \%)$ and $92.3 \%$ (91.4\% to $93.1 \%$ ), respectively. Caffeine consumption during the entire pregnancy and the first, second and third trimesters were not associated with ADHD in the crude or adjusted analysis.

Conclusions: The present study did not show any association between maternal caffeine consumption during pregnancy and ADHD at the age of 11 years.

\section{INTRODUCTION}

Attention deficit hyperactivity disorder (ADHD) is a neurobiological disorder that affects around $6 \%$ of school-age children around the world. ${ }^{1}$ It is the most prevalent mental disorder during childhood and the

\section{Strengths and limitations of this study}

- This was a longitudinal study with a low percentage of losses and refusals at the follow-ups.

- Detailed information on caffeine consumption from coffee and yerba mate during the three trimesters of pregnancy was available.

- Information on a number of potential confounding factors was gathered and formally tested.

- The reported amount of coffee and yerba mate consumed during pregnancy may be subject to recall bias.

- Only two sources of caffeine (coffee and yerba mate) were assessed.

main reason why mental health services are sought for children and adolescents. ${ }^{2}$ It is characterised by persistent symptoms of inattention, impulsivity and hyperactivity, which present before the age of 12 years and are abnormal for the developmental stage. ${ }^{3}$

ADHD is a multifactorial disease with complex aetiology and a large genetic component (heritability estimated as $76 \%)^{4}$ Epidemiological studies have shown higher prevalence among boys and among children belonging to families with worse socioeconomic conditions. ${ }^{5-13}$ Maternal caffeine consumption ${ }^{14}$ as well as other nutritional factors during pregnancy, such as intake of folic acid, ${ }^{15}$ iron ${ }^{16}$ and omega- $3^{17}$ have been investigated as determinants of ADHD. In animals, intrauterine exposure to caffeine was associated with increased motor activity, thus suggesting a possible effect on attention deficit and hyperactivity in children born to mothers with high consumption of caffeine-rich foods and beverages during pregnancy. ${ }^{18}{ }^{19}$ Moreover, exposure of rats to caffeine, during the prenatal period, resulted in gene expression alterations relating to the formation of synapses, thereby showing some of the potential molecular effects of caffeine during fetal cerebral development. ${ }^{20}$ 
Caffeine is commonly consumed throughout the world, including pregnant women, whose daily consumption ranges from $75 \%$ to $93 \% .^{21}$ Studies evaluating caffeine intake during pregnancy and long-term outcomes, such as children neurobehaviour, are still scarce and their results are inconsistent. Among the five articles identified in a systematic review of the literature ${ }^{22}$ only one found that the higher maternal caffeine intake during pregnancy would increase the risk of ADHD. ${ }^{14}$ The objective of the present study was to evaluate the association between maternal caffeine consumption during pregnancy and ADHD at the age of 11 years, among children belonging to a birth cohort. The hypothesis of the study was that maternal caffeine consumption during pregnancy was associated with ADHD at the age of 11 years.

\section{METHODOLOGY}

In 2004, a birth cohort study was started in the city of Pelotas, Brazil. The original cohort population consisted of the 4231 newborns at five hospitals in the city, who were the children of mothers living in the urban zone of Pelotas, corresponding to $99.2 \%$ of the births in that year. The mothers were interviewed after delivery (perinatal study) by trained interviewers, using standardised questionnaires, regarding their socioeconomic, demographic and reproductive characteristics, use of health services, prenatal attention and pregnancy complications. Further methodological details of the study can be found in other publications. ${ }^{23-25}$

So far, the cohort participants were followed-up at the ages of 3,12, 24 and 48 months, and at 6 and 11 years. The mothers were interviewed regarding their children's growth, development, type of food, and morbidity, and also answered questions about their own health. ${ }^{24}$ Differently from the visits at 3, 12, 24, and 48 months that took place at the child's place, at the age of 6 and 11 years data-gathering was undertaken at a clinic that had been set up especially to attend to this research. Besides interviews, the children underwent a comprehensive health evaluation, which included psychological, psychiatric, anthropometric and body composition evaluations. $^{25}$

The presence of ADHD was evaluated by means of the Development and Well-Being Assessment (DAWBA), an instrument employed for psychiatric diagnosis among children and teenagers aged from 5 to 17 years, and that uses diagnostic classifications from the Diagnostic and Statistical Manual of Mental Disorders, 5th edition (DSM-V) and the International Classification of Diseases, 10th Revision (ICD-10) ${ }^{26}$ DAWBA was reported by mothers during the 11-year follow-up by trained interviewers (psychologists). The DAWBA combines highly structured questions based on DSM-V diagnostic criteria and ICD-10 with qualitative descriptions of all areas of difficulty. The generating program is a computer algorithm that provides the probability of a child to have any psychiatric disorder based on answers to structured questions. In the presence of positive symptoms in any area, additional questions (qualitative assessment) are prepared to assess the impact (loss) of these problems in the child's life. These questions concern specific areas covering distress and interference with family life, learning, friendship and leisure activities resulting in symptoms. Subsequently, a clinical evaluator, based on the collected information, combines the quantitative results with the qualitative date and makes a judgement in regard to the presence or absence of the disorder. The clinic trial in this case was made by a child psychiatrist (rater), supervised by another child psychiatrist, who translated and validated the DAWBA for the Brazilian population. To make the psychiatric diagnosis from DAWBA evaluations, the rater needs to judge whether symptoms are present or not and the loss (impact) that they cause. DAWBA diagnoses are supplied dichotomously as 'yes' or 'no', strictly respecting the diagnostic criteria defined by ICD-10 and DSM-V diagnostic classifications. For this study the DSM-V classification was employed. DAWBA allows the identification of children currently under treatment for ADHD, such children were classified as positive for ADHD. The DAWBA questionnaire was translated and validated in Brazil by Fleitlich-Bilyk and Goodman. ${ }^{26}$

The daily caffeine consumption during pregnancy was evaluated at the perinatal study by means of a series of questions regarding consumption of foods that are the main sources of caffeine at this region of the country: coffee and yerba mate (a typical hot beverage consumed in southern Brazil and neighbouring countries, which is prepared from the leaves of the herb Ilex paraguariensis). For each source of caffeine, the daily frequency of consumption was obtained, separately for each trimester of pregnancy. Information regarding the type of coffee (filtered or instant), preparation, concentration (strong, medium or weak) and quantity consumed per day according to the size of the recipient used for drinking coffee $(180 \mathrm{~mL}$ cup; $50 \mathrm{~mL}$ small cup; $200 \mathrm{~mL}$ glass and190 $\mathrm{mL}$ mug) was gathered. The estimated caffeine content from coffee and yerba mate was obtained from coffee samples collected from the homes of mothers who participated in a previous study conducted in the city of Pelotas, ${ }^{27}$ and were analysed by chromatography. From these analyses, it was possible to infer the average caffeine content in milligram per millilitre of coffee, according to the concentration at which it was consumed: strong coffee, $0.25 \mathrm{mg} / \mathrm{mL}$; medium coffee, $0.20 \mathrm{mg} / \mathrm{mL}$; and weak coffee, $0.11 \mathrm{mg} / \mathrm{mL}$. For yerba mate, the analyses showed an average concentration of $17 \mathrm{mg}$ of caffeine per $100 \mathrm{~mL}$ of the liquid. These results were used to estimate the caffeine intake of the entire sample. For instant coffee, the items investigated were the size of the spoon that was used to serve coffee (full coffee spoon, $2.6 \mathrm{~g}$; level coffee spoon, $2.3 \mathrm{~g}$; full small coffee spoon, $2.5 \mathrm{~g}$; level small coffee spoon, $1.5 \mathrm{~g}$; full dessert spoon, $7.5 \mathrm{~g}$; and level dessert spoon, $7.0 \mathrm{~g}$ ) 
and the number of spoons per portion. The spoon sizes were obtained from home measurements. Photographs of spoons were used during interviews to avoid classification errors. For instant coffee, the information used was provided by the manufacturer: an average of $3 \mathrm{mg}$ of caffeine per gram of powdered coffee. For each mother, the average daily caffeine intake was calculated per trimester and during the entire pregnancy.

Potential confounding factors in the association between maternal caffeine consumption during pregnancy and ADHD were gathered at the perinatal study and considered in the adjusted analysis: National Economic Index (acronym IEN in Portuguese) presented in quintiles (in which mothers at quartile 1 (Q1) were the poorest and at Q5 were the wealthiest); mother's and father's education levels, evaluated as years of study; maternal age, evaluated as complete years at the delivery; mother living with or without partner; number of cigarettes smoked per day by the mother during pregnancy; number of cigarettes smoked per day by the father in the mother's presence during pregnancy; alcohol consumption by the mother during pregnancy (yes or no); number of antenatal care consultations; mood symptoms during pregnancy (through the question 'During pregnancy, did you feel depressed or nervous?'); maternal nutritional state before pregnancy, evaluated according to the body mass index (BMI) and categorised as underweight $\left(<18.5 \mathrm{~kg} / \mathrm{m}^{2}\right)$, normal weight $\left(18.5-24.9 \mathrm{~kg} / \mathrm{m}^{2}\right)$, overweight $\left(25-29.9 \mathrm{~kg} / \mathrm{m}^{2}\right)$ or obese $\left(\geq 30 \mathrm{~kg} / \mathrm{m}^{2}\right)$; the child gestational age at birth; birth weight; and sex of the child.

Twins were not included in the analyses $(\mathrm{N}=84)$. The prevalence of ADHD and respective 95\% CI was calculated for the entire cohort and separately by sex (based on the current literature that consistently reports higher prevalence rates among boys). ${ }^{5-13}$ The association between maternal caffeine consumption grouped in three categories $<100,100-299$ and $\geq 300 \mathrm{mg} /$ day and ADHD was evaluated by means of the $\chi^{2}$ test. The strength of association between caffeine consumption grouped in three categories and ADHD was ascertained for the entire cohort and after stratification by sex, by means of logistic regression (crude and adjusted for confounding factors). In addition, analyses were performed with daily caffeine intake as a continuous variable.

A conceptual framework previously built by the authors describing the postulated hierarchical relationships between exposures (figure 1) was used to drive the inclusion of potential confounders to the analytical model. Maternal mental health during pregnancy was the first variable included in the model, followed by father years of school and maternal sociodemographic characteristics (IEN, years of school, age and marital status). Subsequently the behavioural variables were added (maternal smoking and alcoholic beverage intake during pregnancy, paternal smoking during pregnancy, and number of antenatal care consultations). Only
LEVEL I

Maternal mental health during pregnancy

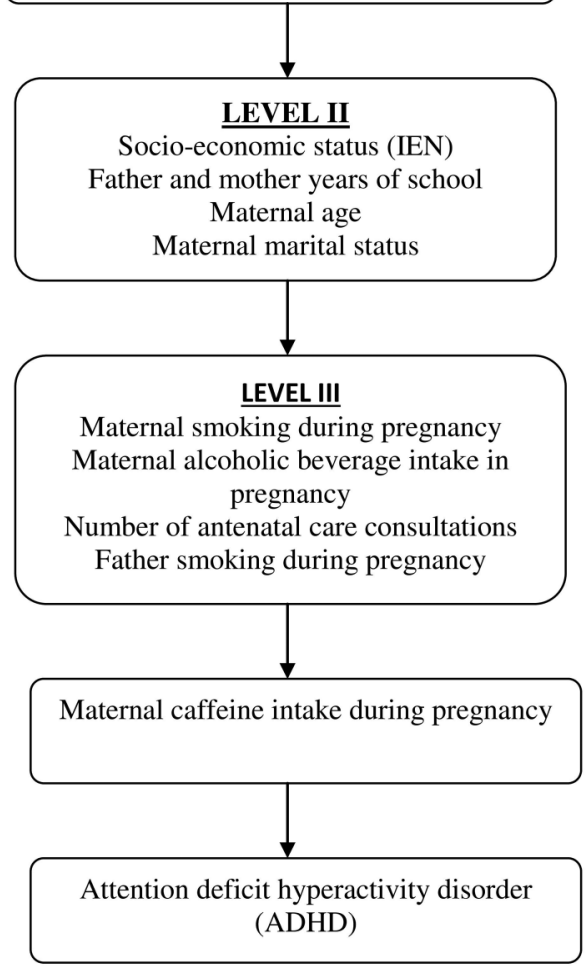

Figure 1 Conceptual framework for the association between maternal caffeine consumption during pregnancy and offspring ADHD at the age of 11 years. ADHD, attention deficit hyperactivity disorder; IEN, National Economic Index.

variables associated with the outcome at $p$ values $\leq 0.20$ were considered at the final model.

Loss to follow-up rates according to some of the child's parents characteristics were not homogeneously distributed, the effect of missing outcome data was analysed as sensitivity analysis, estimated by multiple imputation (mi Stata command) by the Bayesian paradigm from the frequentist (randomisation-based) perspective. Least squares regression and 20 multiple datasets for the missing values were used.

The Pelotas 2004 Birth Cohort Study was approved by the Research Ethics Committee of the Medical School of the Federal University of Pelotas that is affiliated to the Brazilian National Commission for Research Ethics. All mothers signed an informed consent form at each follow-up, after being informed of the study objectives.

\section{RESULTS}

The present study used data from the perinatal study that included 4231 newborns and the follow-up at the age of 11 years (mean age of 10.9 ; SD 0.3 years) that included 3566 children (follow-up rate of $86.6 \%$ ). A total of 3485 mothers and their children $(82.4 \%$ of the original cohort) had full information on caffeine intake 
and on ADHD and were considered in the current analyses.

Table 1 shows the loss to follow-up rate at 11 years according to maternal caffeine intake during the entire pregnancy, IEN, paternal education level, mother living with or without a partner, and maternal mood symptoms during pregnancy. There were no differences in losses to follow-up by the level of caffeine intake throughout pregnancy. Losses were higher for children from families in the extremes of IEN $(18.9 \%$ among the poorest and $15.8 \%$ among the richest), with highly educated fathers $(20.8 \%)$. Greater proportion of losses was also seen among children of mothers who lived with a partner and presented mood symptoms during pregnancy (table 1).

The prevalence of ADHD was $4.1 \%$ (3.4\% to $4.7 \%$ ): $5.8 \%(4.7 \%$ to $6.9 \%)$ among boys and $2.3 \%$ (1.5\% to $3.0 \%$ ) among girls. Table 2 shows the sample distribution and the prevalence of ADHD according to family and child variables. ADHD was more frequent among children from families of lower socioeconomic status (first quintile of IEN), from less-educated mothers (04 years of formal education), living without a partner, those who had attended to $<6$ antenatal care consultations, who smoked more than 10 cigarettes a day and consumed alcoholic beverages during pregnancy. ADHD was also more frequent in children from less-educated fathers (0-4 years of schooling) and among boys.

Table 3 shows the prevalence and intensity of caffeine intake during pregnancy and the prevalence of ADHD among children of mothers who consumed between 100 and $299 \mathrm{mg} /$ day or 300 or more $\mathrm{mg} /$ day of caffeine, compared with those from mothers who consumed $<100 \mathrm{mg} /$ day, taken as the reference group. The prevalence of caffeine consumption during the entire pregnancy and in the first, second and third trimesters was $88.7 \%(87.7 \%$ to $89.7 \%), 86.5 \% \quad(85.4 \%$ to $87.5 \%)$, $83.0 \%(81.8 \%$ to $84.2 \%)$ and $92.3 \%$ (91.4\% to $93.1 \%)$, respectively. Most of the mothers consumed $<100 \mathrm{mg} /$ day of caffeine in the entire pregnancy period and in each trimester of pregnancy, whereas nearly one in every five mothers consumed $\geq 300 \mathrm{mg} /$ day in every trimester and throughout pregnancy. Heavy caffeine consumers were more likely to belong to families from the low socioeconomic strata and present behavioural exposures (smoking and consumption of alcoholic beverages during pregnancy) than the other mothers. Caffeine-consuming mothers attended a fewer number of antenatal care consultations and presented mood symptoms during pregnancy more frequently than nonconsumers (data not shown). There was no difference in ADHD prevalence according to the mean amount of maternal daily caffeine consumption (table 2).

The results of crude and adjusted analyses of the association between caffeine intake in three categories (<100, 100-299 and $\geq 300 \mathrm{mg} /$ day) per trimester and during the entire pregnancy and ADHD are presented in table 4. There was no association between caffeine consumption and ADHD, both in the crude and in the
Table 1 Sociodemographic characteristics of mothers and children enrolled in the 2004 Pelotas Birth Cohort, and loss to follow-up rate at 11 -year

\begin{tabular}{lrrr}
\hline Variables & $\begin{array}{l}\text { Perinatal } \\
\text { study } \\
\mathbf{N}(\%)\end{array}$ & $\begin{array}{l}\text { Loss to } \\
\text { follow-up } \\
\text { rate }\end{array}$ & p Value \\
\hline $\begin{array}{l}\text { Caffeine intake in the } \\
\text { entire pregnancy, }\end{array}$ & & & 0.338 \\
mg/day & & & \\
$<100$ & 1534 & 17.1 & \\
100-299 & 902 & 14.4 & \\
$\geq 300$ & 698 & 16.6 & $<0.001$ \\
IEN & & & \\
Q1 & 641 & 18.9 & \\
Q 2 & 659 & 13.4 & \\
Q 3 & 623 & 10.0 & \\
Q 4 & 640 & 8.8 & \\
Q 5 & 639 & 15.8 & \\
Paternal education & & & \\
level & & & \\
1-4 & 568 & 17.1 & \\
5-8 & 1133 & 16.2 & \\
9-11 & 1159 & 14.1 & \\
12 or more & 375 & 20.8 & \\
Maternal conjugal & & & \\
situation & & & \\
With partner & 3468 & 20.5 & \\
Without partner & 679 & 15.3 & \\
Maternal mood & & & \\
symptoms in & & & \\
pregnancy & & & \\
No & 3107 & 14.9 & \\
Yes, treated & 898 & 20.5 & \\
Yes, not treated & 140 & 15.7 & \\
\hline
\end{tabular}

Pelotas 2004 Birth Cohort Study.

IEN, National Economic Index; Q1, quartile 1.

adjusted analysis, during the three pregnancy trimesters and the entire pregnancy. All the 95\% CI of the estimated ORs included the unit, thus showing that there was no association. The same result was shown in the analysis stratified by sex. Analyses with caffeine as a continuous variable also found no association (data not shown).

The multiple imputation data for the primary outcome produced imputed estimates that were similar to the available data. This similarity showed that all analyses were not affected by missing data or differential rates of follow-up.

\section{DISCUSSION}

The present study found a prevalence of ADHD of $4.1 \%$ ( $95 \%$ CI $3.4 \%$ to $4.7 \%$ ): $5.8 \%$ (95\% CI $4.7 \%$ to $6.9 \%$ ) among boys and $2.3 \%$ (95\% CI $1.5 \%$ to $3.0 \%$ ) among girls. This finding is consistent with results from other studies that employed DAWBA as the evaluation tool and the DSM-IV as the diagnostic criterion in Brazil. ${ }^{5} 2829$ The prevalence of ADHD in school children in Brazil 
Table 2 Prevalence of ADHD at the age of 11 years, according to characteristics of the family and the child

\begin{tabular}{|c|c|c|c|}
\hline \multirow[b]{2}{*}{ Variables } & \multicolumn{3}{|c|}{ 11-year follow-up } \\
\hline & $\mathbf{N}(\%)$ & ADHD \% & p Value \\
\hline IEN & 2780 & & $0.003^{*}$ \\
\hline Q1 & $521(18.7)$ & 5.0 & \\
\hline Q2 & $574(20.7)$ & 5.6 & \\
\hline Q3 & $562(20.2)$ & 3.0 & \\
\hline Q4 & $584(21.0)$ & 4.1 & \\
\hline Q5 & 539 (19.4) & 1.9 & \\
\hline Maternal education level in years & 3452 & & $0.003^{*}$ \\
\hline $0-4$ & $512(14.8)$ & 6.8 & \\
\hline $5-8$ & $1429(41.4)$ & 4.1 & \\
\hline $9-11$ & $1175(34.1)$ & 3.2 & \\
\hline 12 or over & $336(9.7)$ & 3.3 & \\
\hline Paternal education level in years & 2717 & & $0.004^{*}$ \\
\hline $0-4$ & $471(17.3)$ & 5.5 & \\
\hline $5-8$ & $952(35.0)$ & 4.5 & \\
\hline $9-11$ & $996(36.7)$ & 3.2 & \\
\hline 12 or over & $298(11.0)$ & 2.0 & \\
\hline Maternal age (years) & 3483 & & $0.291^{*}$ \\
\hline$<20$ & $660(18.9)$ & 4.9 & \\
\hline 20-35 & $2441(70.1)$ & 3.9 & \\
\hline$>35$ & $382(11.0)$ & 3.7 & \\
\hline Maternal marital status & & & $0.001 \dagger$ \\
\hline With partner & $2943(84.5)$ & 3.6 & \\
\hline Without partner & $542(15.6)$ & 7.0 & \\
\hline Number of cigarette smoked per day by the mother & 3485 & & $0.006^{\star}$ \\
\hline 0 & $2618(75.1)$ & 3.7 & \\
\hline $1-9$ & $520(14.9)$ & 4.4 & \\
\hline 10 or more & 347 (10.0) & 6.9 & \\
\hline $\begin{array}{l}\text { Maternal passive smoke (number of } \\
\text { cigarette smoked per day by the father) }\end{array}$ & 2917 & & $0.381^{*}$ \\
\hline 0 & $2458(84.3)$ & 3.7 & \\
\hline $1-9$ & $262(9.0)$ & 3.1 & \\
\hline 10 or more & $197(6.7)$ & 5.6 & \\
\hline Alcohol consumption by the mother during pregnancy & 3485 & & $0.025 \dagger$ \\
\hline No & $3372(96.8)$ & 3.9 & \\
\hline Yes & $113(3.2)$ & 8.8 & \\
\hline Number of antenatal care consultations & 3340 & & $0.006^{*}$ \\
\hline$<3$ & $120(3.6)$ & 5.8 & \\
\hline $3-5$ & $452(13.5)$ & 6.4 & \\
\hline$\geq 6$ & $2768(82.9)$ & 3.5 & \\
\hline Maternal mood symptoms during pregnancy & 3483 & & $0.090 \dagger$ \\
\hline No & $2647(76.0)$ & 3.7 & \\
\hline Yes, not treated & $718(20.6)$ & 5.4 & \\
\hline Yes, treated & $118(3.4)$ & 5.1 & \\
\hline Maternal pre-pregnancy BMI & 2054 & & $0.315^{\star}$ \\
\hline Underweight & 68 (3.3) & 5.9 & \\
\hline Normal weight & $1165(56.7)$ & 3.6 & \\
\hline Overweight & 566 (27.6) & 4.2 & \\
\hline Obese & 255 (12.4) & 5.5 & \\
\hline Gestational age at birth (weeks) & 3464 & & $0.264^{*}$ \\
\hline$<33$ & $39(1.1)$ & 7.7 & \\
\hline 34-36 & $325(9.4)$ & 4.6 & \\
\hline$\geq 37$ & $3100(89.5)$ & 4.0 & \\
\hline Birth weight (grams) & 3484 & & $0.956^{*}$ \\
\hline$<2500$ & $283(8.1)$ & 4.2 & \\
\hline 2500-2999 & $883(25.4)$ & 4.2 & \\
\hline $3000-3499$ & $1395(40.0)$ & 3.9 & \\
\hline$\geq 3500$ & $923(26.5)$ & 4.3 & \\
\hline
\end{tabular}


Table 2 Continued

\begin{tabular}{|c|c|c|c|}
\hline \multirow[b]{2}{*}{ Variables } & \multicolumn{3}{|c|}{ 11-year follow-up } \\
\hline & N (\%) & ADHD \% & p Value \\
\hline Sex & 3485 & & $<0.001 \dagger$ \\
\hline Male & 1803 (51.7) & 5.8 & \\
\hline Female & 1644 (48.2) & 2.3 & \\
\hline
\end{tabular}

ranges from $0.9 \%^{30}$ to $26.8 \% .^{31}$ The former was a population-based study carried out with children aged 5-10 years using clinical criteria (DSM-IV) obtained from two environments (home and school) and taking into account the impact of the symptoms at the child's familial and social relationships. ${ }^{30}$ The later investigated a sample of school children aged 6-15 years employing clinical assessment (DSM-IV), but considering only the report by the teachers and without considering the impact of the symptoms. The variability between the estimates may be due to different factors, from type of sample, evaluation tools, diagnostic criteria, and mainly the source of information (parents, children, adolescents or teachers) ${ }^{32}$ Prevalence of ADHD is generally higher in school samples than in population-based samples. ${ }^{31}$

This study did not show any association between caffeine consumption during pregnancy and ADHD. Contrary to the hypothesis of this study, the crude and adjusted analyses indicated that caffeine had no effect over the occurrence of ADHD. A recent review of the literature showed that there is a scarcity of studies evaluating the effect of caffeine consumption during pregnancy over the occurrence of ADHD, and concluded that the available evidence does not make it possible to confirm or deny the risk that this exposure might present with regard to development of this morbidity during childhood. ${ }^{22}$ The five studies investigating the effect of maternal caffeine consumption over the occurrence of $\mathrm{ADHD}^{22}$ differed in relation to the tools used to measure the outcome: the only one that evaluated the presence of ADHD by means of a diagnostic instrument did not find any association. ${ }^{33}$ The remaining articles used screening tests: Conners' Continuous Performance Test II (CPT-II), ${ }^{34}$ the Child Behavior Checklist $(\mathrm{CBCL})^{8} 14$ and Strengths and Difficulties Questionnaire $(\mathrm{SDQ})^{35}$ and only one found an association $^{14}$ indicating that caffeine consumption during pregnancy would increase the risk of ADHD. The difference between the instruments used for assessing the presence of ADHD generates issues that go beyond the lack of comparability. Screening instruments are more

\begin{tabular}{|c|c|c|c|c|c|c|c|c|c|}
\hline \multirow[b]{2}{*}{ Caffeine consumption } & \multicolumn{3}{|l|}{ Total } & \multicolumn{3}{|l|}{ Boys } & \multicolumn{3}{|l|}{ Girls } \\
\hline & $\mathbf{N}(\%)$ & ADHD & p Value ${ }^{\star}$ & $\mathbf{N}(\%)$ & ADHD & p Value* & $\bar{N}(\%)$ & ADHD & p Value* \\
\hline 1st trimester, mg/day & 3485 & & 0.249 & 1803 & & 0.267 & 1682 & & 0.563 \\
\hline$<100$ & 2072 (59.5) & 3.8 & & $1097(60.8)$ & 5.4 & & $975(58.0)$ & 2.1 & \\
\hline 100-299 & 746 (21.4) & 4.3 & & $360(20.0)$ & 6.1 & & $386(23.0)$ & 3.0 & \\
\hline$\geq 300$ & $667(19.1)$ & 4.8 & & 346 (19.2) & 6.9 & & $321(19.0)$ & 2.5 & \\
\hline 2nd trimester, mg/day & 3483 & & 0.393 & 1803 & & 0.500 & 1680 & & 0.463 \\
\hline$<100$ & $2151(61.8)$ & 3.9 & & 1141 (63.3) & 5.6 & & $1010(60.1)$ & 2.0 & \\
\hline 100-299 & $710(20.4)$ & 4.2 & & 345 (19.1) & 5.8 & & $365(21.7)$ & 2.7 & \\
\hline$\geq 300$ & $622(17.8)$ & 4.7 & & 317 (18.6) & 6.6 & & 305 (18.2) & 2.6 & \\
\hline 3rd trimester, mg/day & 3484 & & 0.151 & 1803 & & 0.368 & 1681 & & 0.141 \\
\hline$<100$ & 2289 (65.7) & 3.9 & & $1216(67.4)$ & 5.7 & & $1073(63.8)$ & 1.9 & \\
\hline $100-299$ & $628(18.0)$ & 3.8 & & 295 (16.4) & 5.1 & & 333 (19.8) & 2.7 & \\
\hline$\geq 300$ & 567 (16.3) & 5.3 & & $292(16.2)$ & 7.2 & & $275(16.4)$ & 3.3 & \\
\hline $\begin{array}{l}\text { Entire pregnancy, } \\
\mathrm{mg} / \text { day }\end{array}$ & 3481 & & 0.40 & 1803 & & 0.475 & 1678 & & 0.350 \\
\hline$<100$ & $2124(61.0)$ & 3.8 & & $1131(62.7)$ & 5.5 & & 993 (59.2) & 1.9 & \\
\hline 100-299 & 773 (22.2) & 4.5 & & $379(21.0)$ & 6.3 & & 394 (23.5) & 2.8 & \\
\hline$\geq 300$ & $584(16.8)$ & 4.6 & & $293(16.3)$ & 6.5 & & 291 (17.3) & 2.8 & \\
\hline
\end{tabular}

${ }^{\star}$ Test for linear trend.

ADHD, attention deficit hyperactivity disorder. 


\begin{tabular}{|c|c|c|c|c|c|c|}
\hline \multirow[b]{2}{*}{ Caffeine consumption } & \multicolumn{2}{|l|}{ Total } & \multicolumn{2}{|l|}{ Boys } & \multicolumn{2}{|l|}{ Girls } \\
\hline & $\begin{array}{l}\text { Crude analysis } \\
\mathrm{N}=3481 \\
\mathrm{OR}(95 \% \mathrm{Cl})\end{array}$ & $\begin{array}{l}\text { Adjusted analysis* } \\
\mathrm{N}=2491 \\
\text { OR }(95 \% \mathrm{Cl})\end{array}$ & $\begin{array}{l}\text { Crude analysis } \\
\mathrm{N}=1803 \\
\mathrm{OR}(95 \% \mathrm{Cl})\end{array}$ & $\begin{array}{l}\text { Adjusted analysis* } \\
\mathrm{N}=1274 \\
\mathrm{OR}(95 \% \mathrm{Cl})\end{array}$ & $\begin{array}{l}\text { Crude analysis } \\
\mathrm{N}=1682 \\
\text { OR }(95 \% \mathrm{Cl})\end{array}$ & $\begin{array}{l}\text { Adjusted analysis }{ }^{*} \\
\mathrm{~N}=1217 \\
\text { OR }(95 \% \mathrm{Cl})\end{array}$ \\
\hline \multicolumn{7}{|c|}{1 st trimester $(\mathrm{N}=3485), \mathrm{mg} / \mathrm{day}$} \\
\hline$<100$ & 1 & 1 & 1 & 1 & 1 & 1 \\
\hline 100-299 & 1.13 (0.74 to 1.72$)$ & 1.04 (0.62 to 1.73$)$ & 1.15 (0.69 to 1.89$)$ & $1.06(0.57$ to 1.98$)$ & 1.27 (0.59 to 2.74$)$ & $1.13(0.44$ to 2.90$)$ \\
\hline$\geq 300$ & $1.27(0.84$ to 1.94$)$ & $0.93(0.55$ to 1.60$)$ & $1.31(0.80$ to 2.14$)$ & $1.06(0.57$ to 1.96$)$ & $1.22(0.53$ to 2.80$)$ & 0.68 (0.21 to 2.17$)$ \\
\hline \multicolumn{7}{|c|}{ 2nd trimester $(\mathrm{N}=3483), \mathrm{mg} / \mathrm{day}$} \\
\hline$<100$ & 1 & 1 & 1 & 1 & 1 & 1 \\
\hline 100-299 & 1.9 (0.71 to 1.66$)$ & $1.03(0.61$ to 1.74$)$ & $1.04(0.62$ to 1.74$)$ & $1.03(0.55$ to 1.94$)$ & 1.39 (0.65 to 3.01$)$ & 1.24 (0.48 to 3.22$)$ \\
\hline$\geq 300$ & $1.20(0.78$ to 1.85$)$ & 0.95 (0.55 to 1.63$)$ & 1.19 (0.72 to 1.99$)$ & 1.09 (0.58 to 2.03$)$ & 1.33 (0.58 to 3.06$)$ & 0.75 (0.24 to 2.38$)$ \\
\hline \multicolumn{7}{|c|}{ 3rd trimester $(\mathrm{N}=3484), \mathrm{mg} / \mathrm{day}$} \\
\hline$<100$ & 1 & 1 & 1 & 1 & 1 & 1 \\
\hline $100-299$ & $0.98(0.62$ to 1.56$)$ & $0.96(0.55$ to 1.68$)$ & 0.89 (0.50 to 1.58$)$ & $0.82(0.40$ to 1.68$)$ & $1.46(0.66$ to 3.24$)$ & $1.68(0.64$ to 4.40$)$ \\
\hline$\geq 300$ & $1.38(0.90$ to 2.11$)$ & 1.05 (0.61 to 1.81$)$ & $1.28(0.78$ to 2.14$)$ & 1.07 (0.57 to 2.02$)$ & $1.78(0.80$ to 3.95$)$ & $1.22(0.41$ to 3.60$)$ \\
\hline \multicolumn{7}{|c|}{ Entire pregnancy $(n=3481), m g /$ day } \\
\hline$<100$ & 1 & 1 & 1 & 1 & 1 & 1 \\
\hline $100-299$ & $1.19(0.79$ to 1.79$)$ & $1.12(0.68$ to 1.84$)$ & $1.16(0.72$ to 1.90$)$ & 1.05 (0.57 to 1.92$)$ & 1.47 (0.69 to 3.12$)$ & 1.46 (0.58 to 3.68$)$ \\
\hline$\geq 300$ & $1.22(0.78$ to 1.91$)$ & $0.90(0.51$ to 1.59$)$ & $1.20(0.70$ to 2.03$)$ & $1.01(0.52$ to 1.95$)$ & 1.45 (0.69 to 3.35$)$ & $0.82(0.25$ to 2.65$)$ \\
\hline
\end{tabular}


sensitive and less specific, and have a high capacity to recognise true positives, but they fail to discard false positives, thereby wrongly identifying healthy individuals as ill. For instance, in an analysis of data from another cohort conducted in Pelotas (the Pelotas 1993 Birth Cohort Study), to estimate the prevalence of psychiatric diseases among children aged 11 years, Anselmi et $a l^{29}$ compared the results from DAWBA with those from the SDQ, which is a screening instrument. They found that as a screening instrument for $\mathrm{ADHD}$, SDQ presented weak performance, with a positive predictive value (PPV) of $48.2 \%$ and a negative predictive value (NPV) of $90.2 \%$. Similar results have been found in other Brazilian studies. $^{26} 30$

There is a high interindividual variability in the physiological response to caffeine consumption that may in part be due to genetic characteristics. The genes involved in caffeine metabolism, such as cytochrome P450 1A2 (CYP1A2), and in caffeine responses in the central nervous system, such as the adenosine $2 \mathrm{~A}$ receptor (ADORA2A), have been the main targets of genetic studies in this area. ${ }^{36-41}$ Polymorphisms in genes in these pathways have been correlated with the habit of consuming coffee and have been shown to be important to modulate the response to caffeine consumption among adults, such as symptoms of anxiety, cognitive performance and insomnia. ${ }^{36-41}$ On the other hand, little is known about the molecular response mechanisms to caffeine in the central nervous system while it is still developing; or about the way in which gene polymorphisms along these pathways might model the response to caffeine. Future studies adding genetic factors to caffeine consumption during pregnancy could contribute towards better understanding the potential role that caffeine may play in the development of ADHD and other psychiatric disorders.

The present study has some strengths and limitations. Among the strengths is the fact that this was a longitudinal study with data from a birth cohort of about 4000 children, which facilitates the generalisation of data. The longitudinal analysis is characterised by following up individuals over a period of time, which ensures that the temporal relationship between exposures and outcomes can be ascertained. Hence, among all the observational study designs this is the ideal for investigating the topic in question. Furthermore, detailed information on caffeine consumption from coffee and yerba mate during the three trimesters of pregnancy was available. The outcome was evaluated by means of an instrument that had been adapted and validated for the Brazilian population, which made it possible to confirm the diagnoses of ADHD. ${ }^{26}$ Moreover, there was the possibility of controlling the analysis for a number of potential confounding factors. Also noteworthy is the low percentage of losses and refusals during the follow-up of the study (13.4\% from birth to 11 years of age). Post-hoc analyses indicated that the study had a power of $82 \%$ to detect as statistically significant ORs $\geq 1.5$, setting $\alpha$ at 0.05 two-tailed.
Some limitations of the study need to be taken in consideration. The lack of information on the presence of ADHD in the mothers is among the limitations. Perhaps mothers with some degree of ADHD may not consider excessive activity in her child as unusual. In addition, the amount of coffee and yerba mate consumed during pregnancy may have been subject to recall bias. Also, although caffeine consumption during pregnancy was assessed from the two main sources (coffee and mate) there are other caffeine sources (foods like chocolate, chocolate drink and cola-drinks as well as medicines) that were not measured. However, daily consumption from other sources is low in this population representing $<10 \%$ of all caffeine consumed by pregnant women. ${ }^{27}$ The findings of this study can be generalised to other settings with socioeconomic characteristics similar to that of Pelotas and where women largely consume caffeine during pregnancy.

\section{CONCLUSION}

There is no evidence from the present study to support any deleterious effect of caffeine consumption during pregnancy over the occurrence of ADHD in the offspring.

Contributors BD-P and ISS contributed to the design of the manuscript, carried out the initial analyses, drafted the initial manuscript, and approved the final manuscript as submitted. AM and ISS designed the data collection instruments, and coordinated and supervised data collection, critically reviewed the manuscript, and approved the final manuscript as submitted. LT-R, LA and TNM drafted the manuscript, critically reviewed it, and approved the final manuscript as submitted.

Funding This article is based on data from the study 'Pelotas Birth Cohort, 2004' conducted by Postgraduate Program in Epidemiology at Universidad Federal de Pelotas, with the collaboration of the Brazilian Public Health Association (ABRASCO). From 2009 to 2013, the Wellcome Trust supported the 2004 birth cohort study. The 11-year follow-up was also funded by the São Paulo Research Foundation-FAPESP (grant number 2014/13864-6). The World Health Organization, National Support Program for Centers of Excellence (PRONEX), Brazilian National Research Council (CNPq), Brazilian Ministry of Health, Children's Pastorate supported previous phases of the study. ISS and AM are supported by the CNPq.

Disclaimer The funding authorities had no involvement in study design; in the collection, analysis and interpretation of data; in the writing of the report; in preparation of the article; nor in the decision to submit the article for publication.

Competing interests None declared.

Patient consent Obtained.

Ethics approval Cômite de ètica em Pesquisa da Faculdade de Medicina da Universidade Federal de Pelotas.

Provenance and peer review Not commissioned; externally peer reviewed.

Data sharing statement Additional data is available by emailing the corresponding author at bianca.delponte@gmail.com.

Open Access This is an Open Access article distributed in accordance with the Creative Commons Attribution Non Commercial (CC BY-NC 4.0) license, which permits others to distribute, remix, adapt, build upon this work noncommercially, and license their derivative works on different terms, provided the original work is properly cited and the use is non-commercial. See: http:// creativecommons.org/licenses/by-nc/4.0/ 


\section{REFERENCES}

1. Polanczyk G, de Lima MS, Horta BL, et al. The worldwide prevalence of ADHD: a systematic review and metaregression analysis. Am J Psychiatry 2007;164:942-8.

2. Biederman J. Attention-deficit/hyperactivity disorder: a selective overview. Biol Psychiatry 2005;57:1215-20.

3. Association AP. Diagnostic and Statistical Manual of Mental Disorders (DSM-5尺). American Psychiatric Pub, 2013.

4. Faraone SV, Perlis $\mathrm{RH}$, Doyle $\mathrm{AE}$, et al. Molecular genetics of attention-deficit/hyperactivity disorder. Biol Psychiatry 2005;57:1313-23.

5. Anselmi L, Menezes A, Barros FC, et al. Early determinants of attention and hyperactivity problems in adolescents: the 11-year follow-up of the 1993 Pelotas (Brazil) birth cohort study. Cad Saude Publica 2010;26:1954-62.

6. Biederman J, Milberger S, Faraone SV, et al. Family-environment risk factors for attention-deficit hyperactivity disorder: a test of Rutter's indicators of adversity. Arch Gen Psychiatry 1995;52:464-70.

7. Arnold LE. Sex differences in ADHD: conference summary. $J$ Abnorm Child Psychol 1996;24:555-69.

8. Chiu YN, Gau SSF, Tsai WC, et al. Demographic and perinatal factors for behavioral problems among children aged 4-9 in Taiwan. Psychiatry Clin Neurosci 2009;63:569-76.

9. Cortese S, Angriman M, Maffeis C, et al. Attention-deficit/ hyperactivity disorder (ADHD) and obesity: a systematic review of the literature. Crit Rev Food Sci Nutr 2008;48:524-37.

10. Fleitlich B, Goodman R. Social factors associated with child mental health problems in Brazil: cross sectional survey. BMJ 2001;323:599-600.

11. Gaub M, Carlson CL. Gender differences in ADHD: a meta-analysis and critical review. J Am Acad Child Adolesc Psychiatry 1997;36:1036-45.

12. Rhee SH, Waldman ID, Hay DA, et al. Sex differences in genetic and environmental influences on DSM-III-R attention-deficit/ hyperactivity disorder. J Abnorm Psychol 1999;108:24-41.

13. Petresco S, Anselmi L, Santos IS, et al. Prevalence and comorbidity of psychiatric disorders among 6-year-old children: 2004 Pelotas Birth Cohort. Soc Psychiatry Psychiatr Epidemiol 2014;49:975-83.

14. Bekkhus $M$, Skjøthaug $T$, Nordhagen $R$, et al. Intrauterine exposure to caffeine and inattention/overactivity in children. Acta Paediatr 2010;99:925-8.

15. Scholl TO, Johnson WG. Folic acid: influence on the outcome of pregnancy. Am J Clin Nutr 2000;71:1295s-303s.

16. Parsons AG, Zhou SJ, Spurrier NJ, et al. Effect of iron supplementation during pregnancy on the behaviour of children at early school age: long-term follow-up of a randomised controlled trial. Br J Nutr 2008;99:1133-9.

17. Hibbeln JR, Davis JM, Steer C, et al. Maternal seafood consumption in pregnancy and neurodevelopmental outcomes in childhood (ALSPAC study): an observational cohort study. Lancet 2007;369:578-85.

18. Hughes RN, Beveridge IJ. Sex-and age-dependent effects of prenatal exposure to caffeine on open-field behavior, emergence latency and adrenal weights in rats. Life Sci 1990;47:2075-88.

19. Nakamoto T, Roy G, Gottschalk SB, et al. Lasting effects of early chronic caffeine feeding on rats' behavior and brain in later life. Physiol Behav 1991;49:721-7.

20. Mioranzza S, Nunes F, Marques DM, et al. Prenatal caffeine intake differently affects synaptic proteins during fetal brain development. Int J Dev Neurosci 2014;36:45-52.

21. Kaiser L, Allen LH, American Dietetic Association. Position of the American Dietetic Association: nutrition and lifestyle for a healthy pregnancy outcome. J Am Diet Assoc 2008;108:553-61.
22. Silva BDel P, Anselmi L, Schmidt V, et al. [Caffeine consumption during pregnancy and attention deficit hyperactivity disorder (ADHD): a systematic literature review]. Cad Saude Publica 2015;31:682-90.

23. Barros AJ, da Silva dos Santos I, Victora CG, et al. [The 2004 Pelotas birth cohort: methods and description]. Rev Saude Publica 2006;40:402-13.

24. Santos IS, Barros AJ, Matijasevich A, et al. Cohort profile: the 2004 Pelotas (Brazil) birth cohort study. Int J Epidemiol 2011;40:1461-8.

25. Santos IS, Barros AJ, Matijasevich A, et al. Cohort Profile Update: 2004 Pelotas (Brazil) Birth Cohort Study. Body composition, mental health and genetic assessment at the 6 years follow-up. Int $J$ Epidemiol 2014:43:1437-1437a-f.

26. Fleitlich-Bilyk B, Goodman R. Prevalence of child and adolescent psychiatric disorders in southeast Brazil. J Am Acad Child Adolesc Psychiatry 2004;43:727-34

27. Santos IS, Victora CG, Huttly S, et al. Caffeine intake and low birth weight: a population-based case-control study. Am J Epidemiol 1998;147:620-7.

28. Scott N, Blair PS, Emond AM, et al. Sleep patterns in children with ADHD: a population based cohort study from birth to 11 years. $J$ Sleep Res 2013;22:121-8.

29. Anselmi L, Fleitlich-Bilyk B, Menezes AMB, et al. Prevalence of psychiatric disorders in a Brazilian birth cohort of 11-year-olds. Soc Psychiatry Psychiatr Epidemiol 2010;45:135-42.

30. Goodman R, Dos Santos DN, Nunes AR, et al. The Ilha de Mare study: a survey of child mental health problems in a predominantly African-Brazilian rural community. Soc Psychiatry Psychiatr Epidemiol 2005;40:11-17.

31. Vasconcelos MM, Werner JJr, Malheiros AF, et al. [Attention deficit/ hyperactivity disorder prevalence in an inner city elementary school] Arq Neuropsiquiatr 2003;61:67-73.

32. Faraone SV, Sergeant J, Gillberg C, et al. The worldwide prevalence of ADHD: is it an American condition. World psychiatry 2003;2:104-13.

33. Linnet KM, Wisborg K, Secher NJ, et al. Coffee consumption during pregnancy and the risk of hyperkinetic disorder and ADHD: a prospective cohort study. Acta Paediatr 2009;98:173-9.

34. Barr HM, Streissguth AP. Caffeine use during pregnancy and child outcome: a 7-year prospective study. Neurotoxicol Teratol 1991;13:441-8.

35. Loomans EM, Hofland L, Van der Stelt O, et al. Caffeine intake during pregnancy and risk of problem behavior in 5-to 6-year-old children. Pediatrics 2012;130:e305-13.

36. Cornelis MC, El-Sohemy A, Campos H. Genetic polymorphism of the adenosine $\mathrm{A} 2 \mathrm{~A}$ receptor is associated with habitual caffeine consumption. Am J Clin Nutr 2007;86:240-4.

37. Cornelis MC, Byrne EM, Esko T, et al., Coffee and Caffeine Genetics Consortium. Genome-wide meta-analysis identifies six novel loci associated with habitual coffee consumption. Mol Psychiatry 2015;20:647-56.

38. Byrne EM, Johnson J, McRae AF, et al. A genome-wide association study of caffeine-related sleep disturbance: confirmation of a role for a common variant in the adenosine receptor. Sleep 2012;35:967.

39. Renda G, Committeri G, Zimarino M, et al. Genetic determinants of cognitive responses to caffeine drinking identified from a double-blind, randomized, controlled trial. Eur Neuropsychopharmacol 2015;25:798-807.

40. Alsene K, Deckert J, Sand P, et al. Association between A2a receptor gene polymorphisms and caffeine-induced anxiety. Neuropsychopharmacology 2003;28:1694-702.

41. Yang A, Palmer AA, de Wit H. Genetics of caffeine consumption and responses to caffeine. Psychopharmacology (Berl) 2010;211:245-57. 